\title{
Usefulness of real time PCR to quantify parasite load in serum samples from chronic Chagas disease patients
}

Myllena F Melo ${ }^{1,4 \dagger}$, Otacilio C Moreira ${ }^{1,4^{*}+}$, Priscila Tenório ${ }^{2}$, Virginia Lorena ${ }^{2,4}$, Izaura Lorena-Rezende ${ }^{2}$, Wilson Oliveira Júnior ${ }^{3}$, Yara Gomes ${ }^{2,4}$ and Constança Britto ${ }^{1,4}$

\begin{abstract}
Background: Inconclusive results of serological diagnosis in Chagas disease have an important impact on blood banks worldwide, reflecting in the high number of discarded bags or in an increased transmission by blood transfusion. Molecular techniques such as qPCR have been used for diagnosis and to monitor Trypanosoma cruzi load in peripheral blood samples. A promising perspective refers to the possibility of parasite DNA detection in serum, taking advantage in using the same samples collected for serological screening.
\end{abstract}

Methods: In order to evaluate the effectiveness of a qPCR strategy for detecting and quantifying T. cruzi DNA in serum, we selected 40 chronic Chagas disease patients presenting different clinical manifestations: Cardiac (23), Digestive (4), Mixed form [cardiodigestive] (7), and asymptomatic (6). Twenty seronegative individuals from non-endemic areas were included as controls. Samples were extracted using QIAamp DNA mini kit (QIAGEN) and QPCR was performed in a multiplex format with TaqMan probes for the nuclear satellite DNA of T. cruzi and for the human RNase P gene. In addition, DNA migration to serum during blood coagulation was assessed using a commercial exogenous control (Exo IPC, Applied Biosystems) in a separate qPCR reaction.

Results: The comparative duplex qPCR analysis revealed that, even with an increase in Ct values, it was possible to detect all DNA targets in serum. In addition, the same linearity range for $T$. cruzi quantification (from $10^{5}$ to 0.5 par. eq./mL) between serum, blood or culture samples (T. cruzi epimastigotes - Cl Brener strain) was found. When patient samples were evaluated, no significant differences in parasite load between the distinct clinical manifestations were found for both blood and serum samples. Moreover, median values of parasite burden were 1.125 and 1.230 par. eq./mL for serum and blood, respectively. Using serology as gold standard, we found $95 \%$ sensitivity for T. cruzi detection in serum and $97.5 \%$ for blood, and $100 \%$ specificity for both samples.

Conclusions: Taken together, our data indicate the potential of using serum samples for molecular diagnosis and parasite load quantification by $\mathrm{qPCR}$, suggesting its use in reference laboratories for the diagnosis of Chagas disease patients.

Keywords: Molecular diagnosis, Real Time PCR, Chagas disease, Serum samples

\footnotetext{
* Correspondence: otacilio@ioc.fiocruz.br

${ }^{\dagger}$ Equal contributors

'Laboratório de Biologia Molecular e Doenças Endêmicas, IOC /Fiocruz, Av. Brasil, 4365. Pavilhão Leônidas Deane, sala 209. Manguinhos, Rio de Janeiro, Brazil

${ }^{4}$ Programa Integrado de Doença de Chagas/Fiocruz, Rio de Janeiro, RJ, Brazil Full list of author information is available at the end of the article
} 


\section{Background}

Chagas disease is caused by the protozoan Trypanosoma cruzi and represents the third-highest parasitic disease burden after malaria and schistosomiasis [1,2]. It remains a relevant and endemic public health issue in 21 endemic countries of America, with an estimated 8 million people already infected and about 50,000 new cases per year [3,4]. In addition, cases of Chagas disease due to blood transfusion and organ transplantation have been increasingly detected in the United States, Canada, many European countries and Oceania, as consequence of intense migration of Latin America infected individuals to non-endemic countries $[5,6]$. In this context, there is an urgent need for improving the surveillance on neglected tropical diseases for reducing the elevated number of undiagnosed Chagas disease cases in these countries $[7,8]$.

The current diagnostic methods for Chagas disease are not satisfactory [3], being performed through the detection of parasites (or parts of its content) in blood or the presence of parasite-specific antibodies in patient's serum [9]. The results obtained by serological tests are often inconclusive and available kits are expensive and present rather low reproducibility, due to the use of non-defined reagents. In general, serological doubtful results can bring a significant impact in blood bank screening leading to an increment of discarded blood bags. In Brazil, it is estimated 55,000 seropositive donors $[10,11]$ and the risk of transfusion transmission via contaminated blood is about $12 \%-25 \%$ [12]. In the last decade, concerning the blood banks of Pernambuco state, the proportion of inconclusive serology by two or more tests (indirect haemagglutination, indirect immunofluorescence and enzyme-linked immunosorbent assays) was higher than the concordance of positive results obtained by these tests [13]. In this sense, more reliable diagnostic methods for Chagas disease as well as biomarkers for assessment treatment response are urgently needed $[9,14]$. Quantitative PCR (qPCR) based assays could fill these gaps providing higher sensitivity and specificity than conventional methods to detect and quantify T. cruzi DNA in Chagas disease patients [15-18].

Herein, we evaluated the effectiveness of a duplex qPCR strategy based on TaqMan probes for detection and quantification of $T$. cruzi load in serum samples from chronic Chagas disease patients. Comparing the results obtained with peripheral blood samples, the data indicated the potential of using serum samples for molecular diagnosis and parasite load quantification, thus suggesting the use of qPCR in reference laboratories for the diagnosis of Chagas disease patients.

\section{Methods}

\section{Ethics, consent and permissions}

Forty seropositive Chagas disease chronic patients (aged 18 to 73 with a median of 62 years; 22 females and 18 males) assisted at the Ambulatório de doença de Chagas e Insuficiência Cardíaca do Pronto Socorro Cardiológico de Pernambuco (PROCAPE) - Universidade de Pernambuco (UPE), Brazil participated in the study. The serodiagnosis to confirm the infection was performed by both, conventional and recombinant enzyme-linked immunosorbent assays-CHAGAS TEST ELISA III (ABBOT/BiosChile Bioschile Ingenieria Genética S.A., Santiago, Chile) and Imuno-Elisa CHAGAS (WAMA Diagnóstica, São Carlos, São Paulo, Brasil), following the recommendation of the Ministry of Health of Brazil (Technical Note 03/06CGLAB/CGDT/DEVEP/SVS/MS) [9,19]. Patients were classified accordingly to their clinical manifestations as follows: cardiac (twenty three); digestive (four); cardiodigestive (seven); asymptomatic (six) [9]. Additionally, 20 individuals without $T$. cruzi infection (negative serology) living in non-endemic Chagas disease areas were included as control group. The individuals recruited for this study did not receive any blood transfusion or organ transplantation prior to blood harvesting. The study was approved by the ethical committee of the Centro de Pesquisas Aggeu Magalhães from Fiocruz (CAEE: 0096.0.095.00007), following the principles expressed in the Declaration of Helsinki. Chagas disease patients and healthy individuals participated as volunteers and agreed to the "Terms of Free and Informed Consent"; written informed consents were obtained.

\section{DNA extraction from human blood and serum}

For each individual, ten milliliters of venous blood were collected. Five milliliters were immediately transferred to a BD Vacutainer ${ }^{\circ}$ Plus Plastic Serum tube and remained resting for $30 \mathrm{~min}$ at room temperature, in order to generate the clot from blood cells and the serum phase. The five $\mathrm{mL}$ remaining blood were transferred to a BD Vacutainer ${ }^{\circ}$ Plus Plastic EDTA K3 tube. DNA extraction was performed from $200 \mu \mathrm{L}$ of serum and blood samples, as described by Moreira et al. [20] using the QIAamp DNA Mini kit (Qiagen, Valencia, CA). The DNA eluate was stored at $-20^{\circ} \mathrm{C}$ until use in $\mathrm{qPCR}$ analysis.

\section{Quantitative duplex Real-Time PCR (qPCR)}

The qPCR reactions were carried out with $5 \mu \mathrm{L}$ DNA; $2 \mathrm{X}$ TaqMan ${ }^{\circ}$ Universal PCR Master Mix AmpErase ${ }^{\circ}$ from Applied Biosystems; 300nM cruzi1 (5'ASTCGGCTGATCG TTTTCGA3') and cruzi2 (5'AATTCCTCCAAGCAGCGGATA3') primers and 100nM cruzi3 probe (5'FAM-CA CACACTGGACACCAA-NFQ-MGB3') specific for the satellite region of the nuclear DNA of T. cruzi; 0,5X TaqMan RNAseP Control Reagents kit (VIC/TAMRA) from Applied Biosystems, in a final volume of $20 \mu \mathrm{L}$ [15]. Cycling conditions were a first step at $95^{\circ} \mathrm{C}$ for $5 \mathrm{~min}$, followed by 40 cycles at $94^{\circ} \mathrm{C}$ for $15 \mathrm{sec}$ and $58^{\circ} \mathrm{C}$ for $1 \mathrm{~min}$. The amplifications were carried out in an ABI Prism 7500 Fast device 
(Applied Biosystems, USA). Standard calibration curves for blood and serum were constructed by serial dilution of DNA extracted from blood samples spiked with T. cruzi epimastigotes (CL-Brener), ranging from $10^{5}$ to 0.5 parasite equivalents per milliliter of blood (par. eq. $/ \mathrm{mL}$ ). For serum samples, whole blood was spiked with $T$. cruzi prior to serum preparation and DNA extraction.

\section{Evaluation of DNA migration to serum after blood coagulation}

In order to verify DNA migration to serum after blood coagulation, the TaqMan ${ }^{\odot}$ Exogenous Internal Positive Control Reagents (Exo-IPC DNA) from Applied Biosystems were used. This kit contains a synthetic DNA, without homology with any DNA sequence available on public databanks, together with a set of specific primers and TaqMan probe (VIC/TAMRA). Five milliliters of whole blood samples were spiked with Exo-IPC DNA or T. cruzi CL-Brener epimastigotes to reach a final concentration of $[1 \mathrm{X}]$ or 10 parasites/mL respectively, prior to blood coagulation and serum isolation. DNA extraction and qPCR assays were conducted as described above.

\section{Statistical analysis}

Experiments were performed in five replicates. Data were expressed as arithmetic means or average \pm standard deviation. Student's $t$-test or Mann-Whitney Rank Sum test were used to analyze the statistical significance of the observed differences. A p-value of less than 0.05 was considered statistically significant. All the analyses were performed with Sigmaplot for Windows Version 12.0 (Systat Software, Inc.).

\section{Results}

In this study the potential of serum samples to be used for the detection and quantification of T. cruzi load by real time qPCR was evaluated. At first, to evaluate the DNA migration to serum after blood coagulation, serum, blood and T. cruzi cultivated samples were compared by analyzing the resultant $\mathrm{Ct}$ values in multiplex qPCR assays, where the human RNase P was used as an internal amplification control [15,20], and Exo-IPC was used as an exogenous positive control (Figure 1). For this experiment T. cruzi epimastigotes (CL Brener) were used to contaminate a seronegative blood sample in order to reach final concentration of 10 parasites $/ \mathrm{mL}$ in whole blood, before serum preparation. Following blood coagulation and serum obtaining, it was observed that $T$. cruzi, Exo-IPC and RNAse P targets were detected in DNA extracted from serum samples (Cts means were $32.48,29.38$ and 30.15 , respectively), showing the migration of parasite, exogenous and human DNAs to serum during blood coagulation. Nevertheless, these Ct values

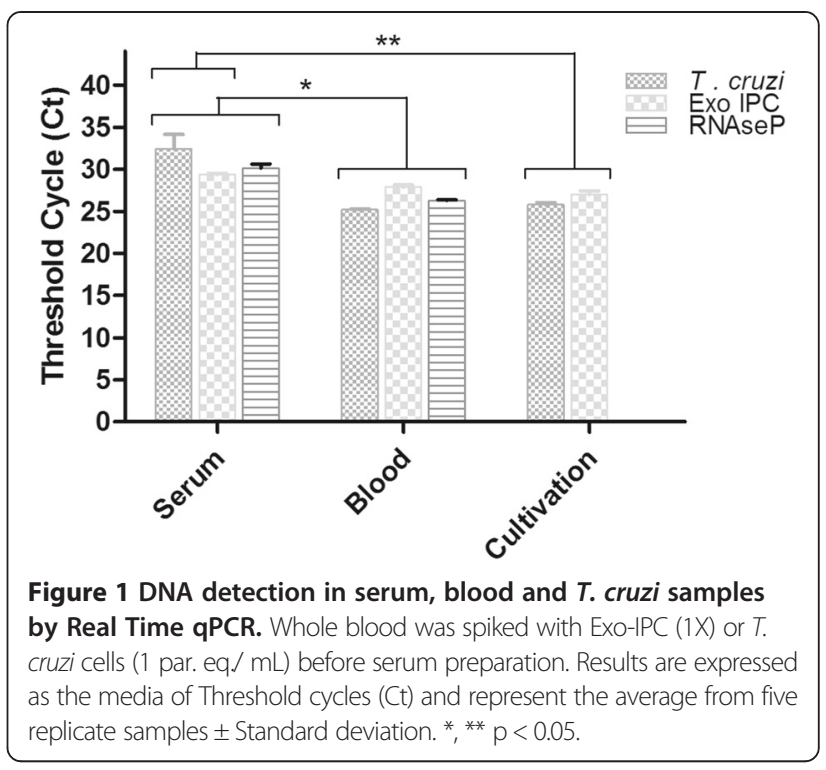

were higher in serum than in blood or cultivated T. cruzi samples ( $\mathrm{p}<0.05$; Ct means for blood samples: 25.22 [ $T$. cruzi]; 27.90 [Exo-IPC] and 26.31 [RNAseP] and Ct means for T. cruzi cultivated samples: 25.79 [T. cruzi] and 27.02 [Exo-IPC]. Even with an increase in Ct values, these results indicated the possibility of parasite detection in serum samples by qPCR.

Aiming to compare the reportable range of $T$. cruzi DNA amplification between blood and serum samples, three independent standard curves were constructed ranging from $10^{5}$ to 0.5 par. eq. $/ \mathrm{mL}$ with DNAs extracted from spiked blood; serum derived from artificially contaminated blood; and T. cruzi DNA from cultured CL Brener epimastigotes (Figure 2). Through linear regression analysis, an increased linearity was observed $\left(R^{2}=0.99\right)$ and adequate slopes $(-3.51,-3.68$ and -3.46 for serum, blood and T. cruzi cultivated samples, respectively) for parasite quantification. The standard curve from serum samples showed higher $\mathrm{Ct}$ values than the ones yielded for blood and cultivated T. cruzi samples, thus revealing lower parasite DNA concentration in serum. Nevertheless, linearity and curve slopes were equal or higher respectively, than those observed for blood standard curve, indicating the potential of serum samples to be used in the quantification of T. cruzi DNA by Real Time qPCR.

In order to compare the sensitivity and specificity of the duplex Real Time qPCR between serum and blood, assays were carried out with a panel of clinical samples from 40 chronic Chagas disease patients and 20 seronegative control patients. Twenty two individuals from the Chagas disease group were female (mean age 57.77 years) and 18 individuals were male (mean age 51.61 years). To calculate the sensitivity and specificity 


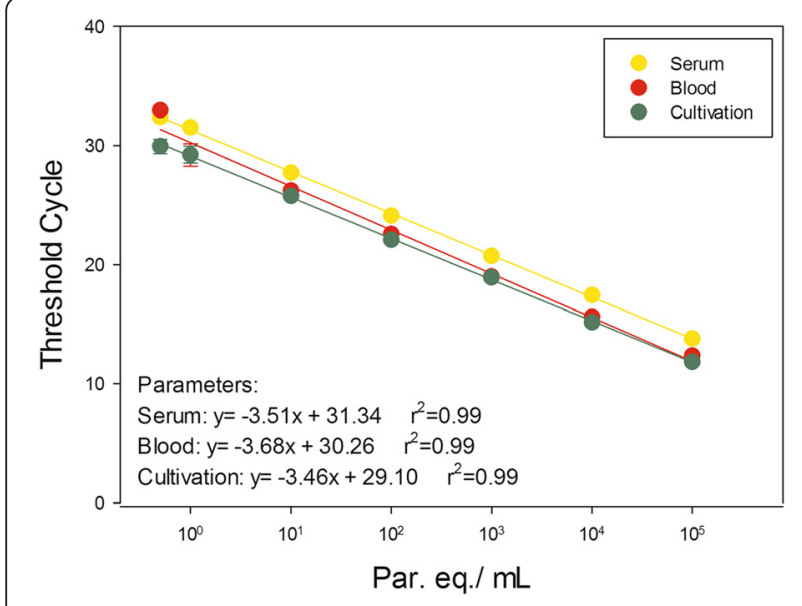

Figure 2 Reportable range for $T$. cruzi detection and quantification by Real Time qPCR. TaqMan qPCR was carried out with serial diluted DNA extracted from serum, blood or parasite cultivated samples, ranging from $10^{5}$ to $0.5 \mathrm{par}$. eq. $/ \mathrm{mL}$, tested in five replicates each. The equations obtained by linear regression are indicated in the chart.

values, serology was considered as gold standard. For each individual, two serological tests using distinct antigens preparation were performed (conventional and recombinant ELISA), and the results were concordant between them. The qPCR showed sensitivities of 97.5 and $95 \%$ for T. cruzi DNA detection in blood and serum samples, respectively, and $100 \%$ specificity for both samples (Table 1).

To estimate parasite load through the multiplex Real Time PCR for absolute quantification, the correspondent standard curves were used for blood and serum samples, as described in Material and Methods section. For blood samples, parasite load varied from 0.067 to 2.553 with a median of 1.23 par. eq./mL. In comparison, for serum samples, the quantification varied from 0.085 to 2.03 with a median of 1.12 par. eq./mL (Figure 3). No significant difference was observed between the median values for these samples. As a matter of fact, the estimated parasite loads for these chronic patients were very low and near the inferior limit of the qPCR dynamic range, which can interfere in the precision of $T$. cruzi quantification.

Table 1 Sensitivity and specificity of the real time qPCR in blood and serum samples

\begin{tabular}{llllll}
\hline & \multicolumn{2}{l}{ Blood samples } & & \multicolumn{2}{l}{ Serum samples } \\
\cline { 2 - 3 } & ELISA + & ELISA - & & ELISA + & ELISA - \\
\hline qPCR + & $39(97.5 \%)$ & $0(0 \%)$ & & $38(95 \%)$ & $0(0 \%)$ \\
qPCR - & $1(2.5 \%)$ & $20(100 \%)$ & & $2(5 \%)$ & $20(100 \%)$ \\
Total & 40 & 20 & & 40 & 20 \\
\hline
\end{tabular}

To calculate Sensitivity and Specificity values, serology was considered as gold standard.

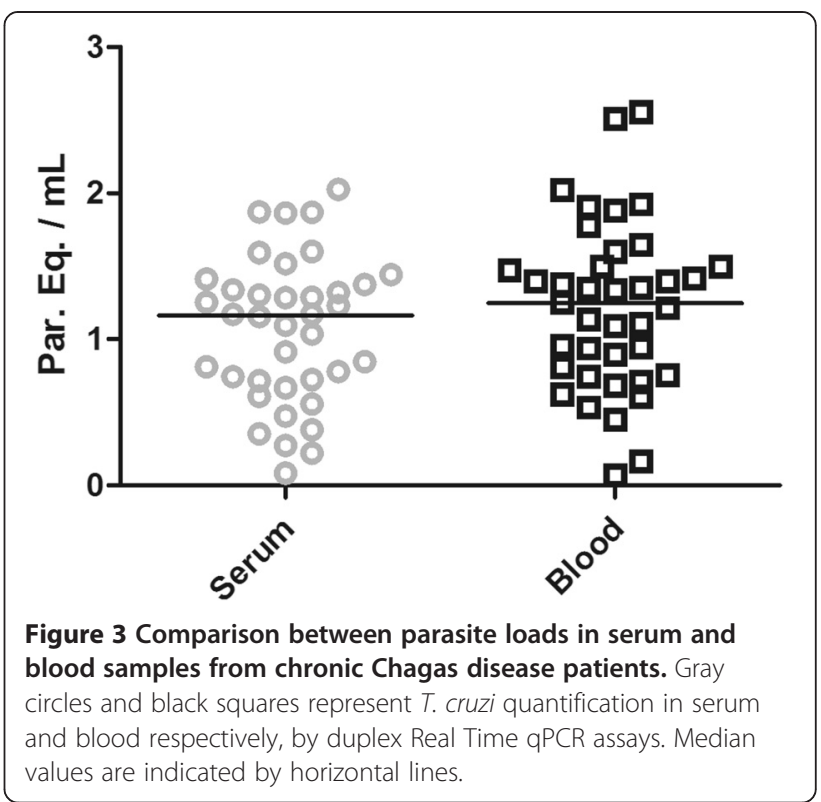

Patients were divided into 4 groups, according to the clinical manifestation of Chagas disease: Cardiac Form $(\mathrm{CF}=23)$, Digestive Form $(\mathrm{DF}=4)$, Indeterminate Form $(\mathrm{IF}=6)$ and Mixed Form $(\mathrm{MF}=7)$. When patients were analyzed according to their clinical manifestations, no significant difference was observed in the parasite load medians between the distinct forms of the disease, even in blood $(\mathrm{MF}=1.11, \mathrm{CF}=1.39, \mathrm{DF}=0.68, \mathrm{IF}=1.18$ par. eq. $/ \mathrm{mL})$ or serum $(\mathrm{MF}=0.85, \mathrm{CF}=1.17, \mathrm{DF}=0.85, \mathrm{IF}=$ 0.86 par. eq. $/ \mathrm{mL}$ ) (Figure 4). Nevertheless, some patients presenting mixed (cardiodigestive) and cardiac forms showed a slight increase in parasitemia in both types of samples. However, as observed in Figure 3, all parasite loads were very low and can compromise the quantification precision.

Although the number of patients evaluated in this study is quite small, our data raised a discussion regarding the application of Real Time qPCR in serum samples for the diagnosis and quantification of T. cruzi, in order to follow-up Chagas disease patients, especially in situations where serum is the only available sample.

\section{Discussion}

Currently, WHO recommends the use of 2 simultaneous serological tests for the diagnosis of chronic Chagas disease, as indirect haemagglutination, indirect immunofluorescence and enzyme-linked immunosorbent assays, based on detection of parasite-specific antibodies [9]. However, there is an elevated number of inconclusive results in blood banks worldwide, resulting in blood bag losses and increasing the risk of transmission by blood transfusion $[5,6,8]$. The Brazilian guideline for chronic Chagas disease diagnosis determines the use of PCR to confirm inconclusive serological tests, resulting in a new 

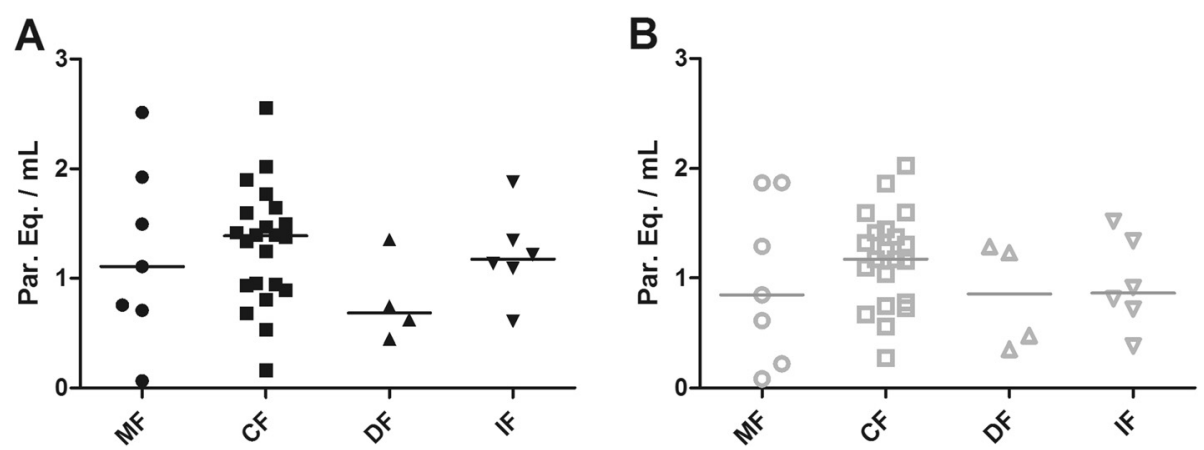

Figure 4 Distribution of parasite loads in blood and serum between chronic patients with distinct clinical manifestations of Chagas disease. A. Black symbols represent parasite loads quantified in blood samples by multiplex Real Time qPCR. B. Gray symbols represent the respective parasite loads in serum samples. Median values are indicated by a straight horizontal line. MF = Mixed Form $(n=7)$; $C F=C$ ardiac Form $(n=23)$; DF = Digestive Form $(n=4)$; IF = Indeterminate Form $(n=6)$.

blood sample collection [9]. In this context, we aimed to investigate the feasibility of Chagas disease molecular diagnosis and parasite load quantification using the same serum sample yielded for serological tests, based on previous studies that confirmed the use of serum samples for T. cruzi DNA detection by PCR [21]. Nevertheless, from our knowledge, this is the first report for using a multiplex Real Time qPCR assay able to detect and quantify $T$. cruzi from serum samples.

In this study, it is evident that the migration of T. cruzi DNA to serum occurs after blood coagulation. When we spiked whole blood with an exogenous DNA or living $T$. cruzi epimastigotes prior to serum isolation, both DNAs could be detected by multiplex Real Time PCR assay, in conjunction with human DNA from nucleated blood cells. As expected, the higher $\mathrm{Ct}$ values observed in serum, in comparison with blood and parasite cultivated samples, indicated that only part of parasite and human DNA migrates to serum after blood coagulation. Nevertheless, the sensitivity for T. cruzi detection in chronic Chagas disease patients was only slightly lower in serum (95.0\%) than blood (97.5\%), and the same specificity (100\%) was observed for both samples (Table 1), which makes it possible to use serum samples to detect T. cruzi DNA by Real Time qPCR. Using serological methods as gold standard, clinical sensitivity for conventional and Real Time PCR assays presents great variability among distinct studies [17,22-26]. In addition, using cruzi1/ cruzi2 primers and cruzi 3 TaqMan probe, Duffy et al. [17] reported sensitivity values ranging from 60.3 $100 \%$ for T. cruzi detection in blood samples from patients from different geographical areas (Venezuela, Cochabamba, Argentina and North Argentina), infected by distinct transmission routes (oral infection, chronic Chagas disease and newborns from chronic Chagas disease mothers), and presenting different parasite load medians $(2.75$ - 691.8 parasite equivalents/ $\mathrm{mL})$. On the other hand, Fitzwater et al. [26] reached 60.1\%, 46.5\% and $40 \%$ sensitivity from clot, buffy coat and whole blood samples, respectively, in a conventional PCR assay using 121/122 primers. Indeed, multiple factors seem to influence these results, as the primers used (kDNA vs Sat-DNA), DNA extraction method, PCR reagents, T. cruzi genotype (DTUs) and parasite load. Following our methodology, even considering low parasite loads, we reached high and similar sensitivity values for blood and serum.

Nowadays, efforts are being done to standardize Real Time qPCR for T. cruzi quantification in blood samples. Following the recommendations from the international workshop promoted by PAHO/WHO in 2011, Duffy et al. [17] reported the analytical performance of a Multiplex Real-Time qPCR for the quantification of $T$. cruzi satellite DNA in blood samples. They observed a reportable range between 1 and $6 \log _{10}$ par. eq. $/ 10 \mathrm{~mL}$ for a TcI isolate (Silvio X10) and 0.25 to $6 \log _{10}$ par. eq./ $10 \mathrm{~mL}$ for a TcVI isolate (CL Brener). In addition, for the CL Brener isolate, it was observed a Limit of Detection (LOD) and Limit of Quantification (LOQ) of 0.6979 and 1.531 par. eq./mL, respectively. Herein, using the same set of primers for $T$. cruzi nuclear satellite DNA multiplexed with human RNAse P gene instead of using the Internal Amplification Control (IAC), we observed a reportable range from $10^{5}$ to 0.5 par. eq. $/ \mathrm{mL}$ (Figure 2) for DNAs extracted from serum, blood or T. cruzi cultivated samples (CL Brener). Likewise, our results were feasible for parasite load quantification in Chagas disease patients with moderated parasitemia.

In this study, the low parasite load achieved in blood or serum samples reproduced the findings observed in recent studies regarding the use of qPCR for chronic Chagas disease patients $[16,17,20]$. The parasite load median in blood (1.23 par. eq./mL) was not statistically different from the one achieved from serum samples (1.12 par. eq./mL) (Figure 3), which corroborates the use of DNA extracted from serum for qPCR assays. 
Nevertheless, comparing with the LOQ previously determined [17], several patients herein analyzed, presented parasite load below the LOQ, which means these samples were detectable but not quantifiable. When patients presenting distinct clinical manifestations were compared (Figure 4), we also could not observe significant differences between the parasite load medians from the groups evaluated, although many patients presenting the cardiac form (CF) seems to have higher parasite load in blood and serum samples. Unfortunately, in this study, there was a limitation concerning the number of analyzed patients, particularly for those with the digestive form of the disease. In the future, a robust investigation joining a representative group of patients with all Chagas disease clinical manifestations will be necessary to properly investigate parasite load as a biomarker for progression and severity of Chagas disease. The advances achieved here suggest the use of serum samples, currently maintained in serum banks, for retrospective studies regarding the disease development and to the follow-up of patients under treatment. Meanwhile, a new study with considerable higher numbers of Chagas disease patients, especially those asymptomatic individuals who can act as potential blood donors, must be performed to validate this molecular diagnostic assay in blood banks worldwide.

\section{Conclusions}

Taken together our data suggest the potential of serum samples to be used for molecular diagnosis and parasite load quantification by quantitative Real Time PCR assays.

\section{Competing interests}

The authors declare that they have no competing interests.

\section{Authors' contributions}

Conceived and designed the experiments: MFM, WOJ, OCM. Performed the experiments: MFM, PT, VL, ILR. Analyzed the data: MM, OCM. Wrote the paper: MFM, OCM, YG, CB. All authors read and approved the final manuscript.

\begin{abstract}
Acknowledgments
The authors thank the Program for Technological Development in Inputs for Health (PDTIS-Fiocruz) for the facilities on the Real Time PCR, the Protozoan Collection from Fiocruz (Colprot) for providing the T. cruzi isolate used in this study and the Doctors Cristina Tavares and Marisa Melo from PROCAPE/UPE for selecting the patients included in this study. This work was supported by grants from PROEP/IOC-Fiocruz/CNPq (National Council for Scientific and Technological Development), Serviço de Referência em Doença de Chagas/ CPqAM/Fiocruz and Fundação Carlos Chagas Filho de Amparo à Pesquisa do Estado do Rio de Janeiro (FAPERJ E-26/110.594/2012 and CNE E-26/102.775/ 2012). C. Britto and Y. Gomes are research fellows of CNPq.
\end{abstract}

\section{Author details}

'Laboratório de Biologia Molecular e Doenças Endêmicas, IOC /Fiocruz, Av. Brasil, 4365. Pavilhão Leônidas Deane, sala 209. Manguinhos, Rio de Janeiro, Brazil. 'Departamento de Imunologia, Centro de Pesquisas Aggeu Magalhães-CPqAM /Fiocruz, Recife, PE, Brazil. ${ }^{3}$ Ambulatório de doença de Chagas e Insuficiência Cardíaca do Pronto Socorro Cardiológico de Pernambuco (PROCAPE), Universidade de Pernambuco (UPE), Recife, PE, Brazil. ${ }^{4}$ Programa Integrado de Doença de Chagas/Fiocruz, Rio de Janeiro, RJ, Brazil.
Received: 18 December 2014 Accepted: 25 February 2015

Published online: 12 March 2015

\section{References}

1. Bern C, Montgomery SP. An estimate of the burden of Chagas disease in the United States. Clin Infect Dis. 2009:49:e52-4.

2. Jackson Y, Ge' taz L, Wolff H, Holst M, Mauris A, Tardin A, et al. Prevalence, clinical staging and risk for blood-borne transmission of Chagas disease among Latin American migrants in Geneva, Switzerland. PLoS Negl Trop Dis. 2010;4:e592.

3. WHO. Research priorities for Chagas disease, human African trypanosomiasis and leishmaniasis. World Health Organ Tech Rep Ser. 2012;975:1-100.

4. Steverding D. The history of Chagas disease. Parasit Vectors. 2014;7:317.

5. Garraud O, Andreu G, Elghouzzi MH, Laperche S, Lefrère JJ. Measures to prevent transfusion-associated protozoal infections in non-endemic countries. Travel Med Infect Dis. 2007;5:110-2.

6. Schmunis GA. Epidemiology of Chagas disease in non-endemic countries: the role of international migration. Mem Inst Oswaldo Cruz. 2007;102 Suppl 1:75-85.

7. Navarro M, Norman FF, Pérez-Molina JA, López-Vélez R. Benznidazole shortage makes Chagas disease a neglected tropical disease in developed countries: data from Spain. Am J Trop Med Hyg. 2012;87:489-90.

8. Basile L, Jansà JM, Carlier Y, Salamanca DD, Angheben A, Seixas J. Working group on Chagas Disease. Chagas disease in European countries: the challenge of a surveillance system. Euro Surveill. 2011;16(37):pii=19968. Available online: http://www.eurosurveillance.org/ViewArticle.aspx? Articleld $=19968$.

9. da Saúde M. Secretaria de Vigilância em Saúde do Ministério da Saúde Consenso Brasileiro em doença de Chagas. Rev Soc Bras Med Trop. 2005;38 Suppl 3:7-29.

10. Amato NV. Conduta frente ao doador chagásico. Rev Soc Bras Med Trop. 1993;26:86-7.

11. Dias JCP. Doença de Chagas e transfusão de sangue no Brasil: vigilância e desafios. Rev Bras Hematol Hemoter. 2006;28:83-4.

12. Lunardelli A, Borges FP, Mello KF, Zeferino ASA. Soroprevalência da doença de Chagas em candidatos a doadores de sangue. Rev Bras Anal Clin. 2007:39:139-41.

13. Melo AS, Lorena V, Moraes $A$, Pinto $M$, Leão $S$, Soares $A$, et al. Prevalência de infecção chagásica em doadores de sangue no estado de Pernambuco, Brasil. Rev Bras Hematol Hemoter. 2009;31:69-73.

14. Pinazo MJ, Thomas MC, Bua J, Perrone A, Schijman AG, Viotti RJ, et al. Biological markers for evaluating therapeutic efficacy in Chagas disease, a systematic review. Expert Rev Anti Infect Ther. 2014;12:479-96.

15. Piron M, Fisa R, Casamitjana N, López-Chejade P, Puig L, Vergés $M$, et al. Development of a real-time PCR assay for Trypanosoma cruzi detection in blood samples. Acta Trop. 2007;103:195-200

16. Duffy T, Bisio M, Altcheh J, Burgos JM, Diez M, Levin MJ, et al. Accurate realtime PCR strategy for monitoring bloodstream parasitic loads in chagas disease patients. PLoS Negl Trop Dis. 2009;3:e419.

17. Duffy T, Cura Cl, Ramirez JC, Abate T, Cayo NM, Parrado R, et al. Analytical performance of a multiplex Real-Time PCR assay using TaqMan probes for quantification of Trypanosoma cruzi satellite DNA in blood samples. PLoS Negl Trop Dis. 2013;7:e2000.

18. Qvarnstrom Y, Schijman AG, Veron V, Aznar C, Steurer F, da Silva AJ. Sensitive and specific detection of Trypanosoma cruzi DNA in clinical specimens using a multi-target real-time PCR approach. PLoS Negl Trop Dis. 2012;6:e1689.

19. Brasil. Ministério da Saúde. Secretaria de Vigilância em Saúde. Departamento de Vigilância Epidemiológica. Coordenação Geral de Laboratórios de Saúde Pública. Resultado da Avaliação dos "kits" para diagnóstico de doença de Chagas. Brasília; 2006. (Nota Técnica № 03/06, CGLAB/CGDT/DEVEP/SVS/MS). (Available from: http://www.biosys.com.br/data/jpf_article/12/file/ avaliacaodoskitsdedoencadechagas.pdf).

20. Moreira OC, Ramírez JD, Velázquez E, Melo MFAD, Lima-Ferreira C, Guh $F$, et al. Towards the establishment of a consensus real-time qPCR to monitor Trypanosoma cruzi parasitemia in patients with chronic Chagas disease cardiomyopathy: a substudy from the BENEFIT trial. Acta Trop. 2013;125:23-31

21. Russomando G, de Tomassone MM, de Guillen I, Acosta N, Vera N, Almiron $\mathrm{M}$, et al. Treatment of congenital Chagas' disease diagnosed and followed up by the polymerase chain reaction. Am J Trop Med Hyg. 1998;59:487-91. 
22. Ávila HA, Pereira JB, Thiemann O, De Paiva E, DeGrave W, Morel CM, et al. Detection of Trypanosoma cruzi in blood specimens of chronic chagasic patients by Polymerase chain reaction amplification of Kinetoplast Minicircle DNA: Comparison with serologic and xenodiagnosis. J Clin Microbiol. 1993;31:2421-6.

23. Schijman AG, Bisio M, Orellana L, Sued M, Duffy T, Mejia Jaramillo AM, et al. International study to evaluate PCR methods for detection of Trypanosoma cruzi DNA in blood samples from Chagas disease patients. PLoS Negl Trop Dis. 2011;5:e931.

24. Gilber SR, Alban SM, Gobor L, Bescrovaine J de J, Myiazaki MI, ThomazSoccol V. Comparison of conventional serology and PCR methods for the routine diagnosis of Trypanosoma cruzi infection. Rev Soc Bras Med Trop. 2013:46:310-5.

25. Ramírez JD, Guhl F, Umezawa ES, Morillo CA, Rosas F, Marin-Neto JA, et al. Evaluation of adult chronic Chagas' heart disease diagnosis by molecular and serological methods. J Clin Microbiol. 2009;47(12):3945-51.

26. Fitzwater S, Calderon M, Lafuente C, Galdos-Cardenas G, Ferrufino L, Verastegui $\mathrm{M}$, et al. Polymerase chain reaction for chronic Trypanosoma cruzi infection yields higher sensitivity in blood clot than buffy coat or whole blood specimens. Am J Trop Med Hyg. 2008;79(5):768-70.

\section{Submit your next manuscript to BioMed Central and take full advantage of:}

- Convenient online submission

- Thorough peer review

- No space constraints or color figure charges

- Immediate publication on acceptance

- Inclusion in PubMed, CAS, Scopus and Google Scholar

- Research which is freely available for redistribution 